\title{
DESIGN AND MANUFACTURE OF A VERY LARGE HOT-GAS EXPANDER IMPELLER IN ALLOY 718 FOR HIGHLY CORROSIVE OFF-GAS
}

\author{
Dr. Sharad Chandra, Klaus D. Mohr, Dr. Volker Schulte \\ MAN TURBO AG, Oberhausen, Germany \\ Dr. Dieter Bokelmann, Jörg Poppenhäger, Karl-Heinz Schönfeld \\ Saarschmiede Freiformschmiede GmbH, Völklingen, Germany
}

Keywords: Hot-gas Expander Impeller, Alloy 718, Largest open die forging

\begin{abstract}
This paper focuses on metallurgical issues and manufacturing of impellers for an integrally geared 2-stage expander for a corrosive hot-gas application. The design employs the largest single piece forging in Alloy 718 material for use in the low pressure stage impeller. Alloy 718 was chosen due to the combination of best corrosion resistance and mechanical properties. With this single piece forging it is possible to manufacture very large impellers in a "non-welddesign". Information about development of the disc production, the manufacturing process and mechanical properties are presented.
\end{abstract}

\section{Introduction}

Since the development of the first MAN TURBO radial expander in the early 1960's, the trend of increasing energy recovery has lead to more efficient expander systems with higher power outputs. Increased power outputs have been achieved through higher gas flow temperatures, bigger mass flows and increased expander sizes. These higher operating temperatures and the large size of the components used in the radial expanders have created new, more difficult demands on the materials and processes employed to make these off-gas expanders. The impeller wheels for the radial expanders have provided a particularly difficult challenge because the class of materials (steel) used to build the radial expanders at the end of the last century, was already stressed to the limits of its temperature, strength and corrosion resistance capabilities.

MAN TURBO develops, designs and manufactures radial expanders (Type ER) according to individual customer specifications to operate up to temperatures of $500^{\circ} \mathrm{C}$ and to be subjected to highly corrosive off-gases. These radial expanders are mainly used in PTA (Purified Terephtalic Acid) processes. The design had to comply with the requirement of avoiding condensation of the off-gas under any operating conditions. Figure 1 shows the 2 Impellers for the High and for the Low Pressure Stage during assembly of the hot-gas expander. These Impellers were made from one single piece forging each and then machined to their intricate aerodynamic design without welding. 
The leading edge MAN TURBO design of the expander rotor requires a single piece impeller with a forged rod on the back-side of the Impeller wheel as shown in the Figure 2. With this special but simple design no welding of the blades to the wheel is necessary to make an Impeller. The problems of reduced corrosion resistance and other serious mechanical properties in the welding joint are completely eliminated.

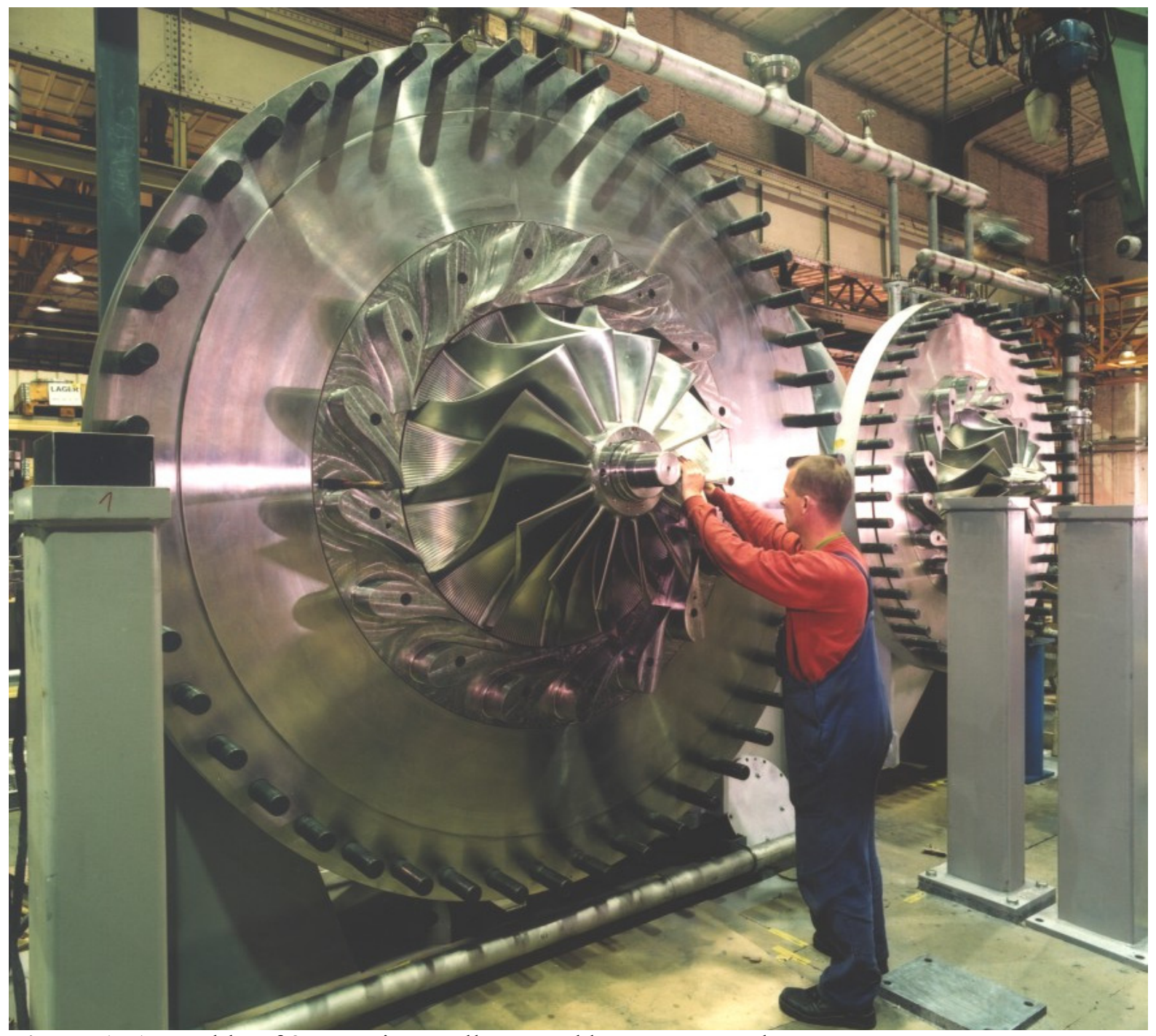

Figure 1: Assembly of 2-stage integrally geared hot-gas expander

In order to avoid condensation it had to be ensured that the expander is always hot when subjected to the hot off-gas. This will be ensured by a warm-up procedure using heated compressor air. The so-called cold-start had to be implemented into the control scheme. A completely buffered labyrinth sealing system has been designed using buffer air from the machinery trains compressor. A CFD calculation of the secondary air system at the impeller back-side has been performed to verify that off-gas is kept out of the critical areas. A detailed transient finite element analysis (FEA) accounting for start-up, upset and run-down conditions, determining the hot and cold clearances of the impeller has been performed to ensure maximum safety and mechanical integrity for this very large hot-gas expander. 

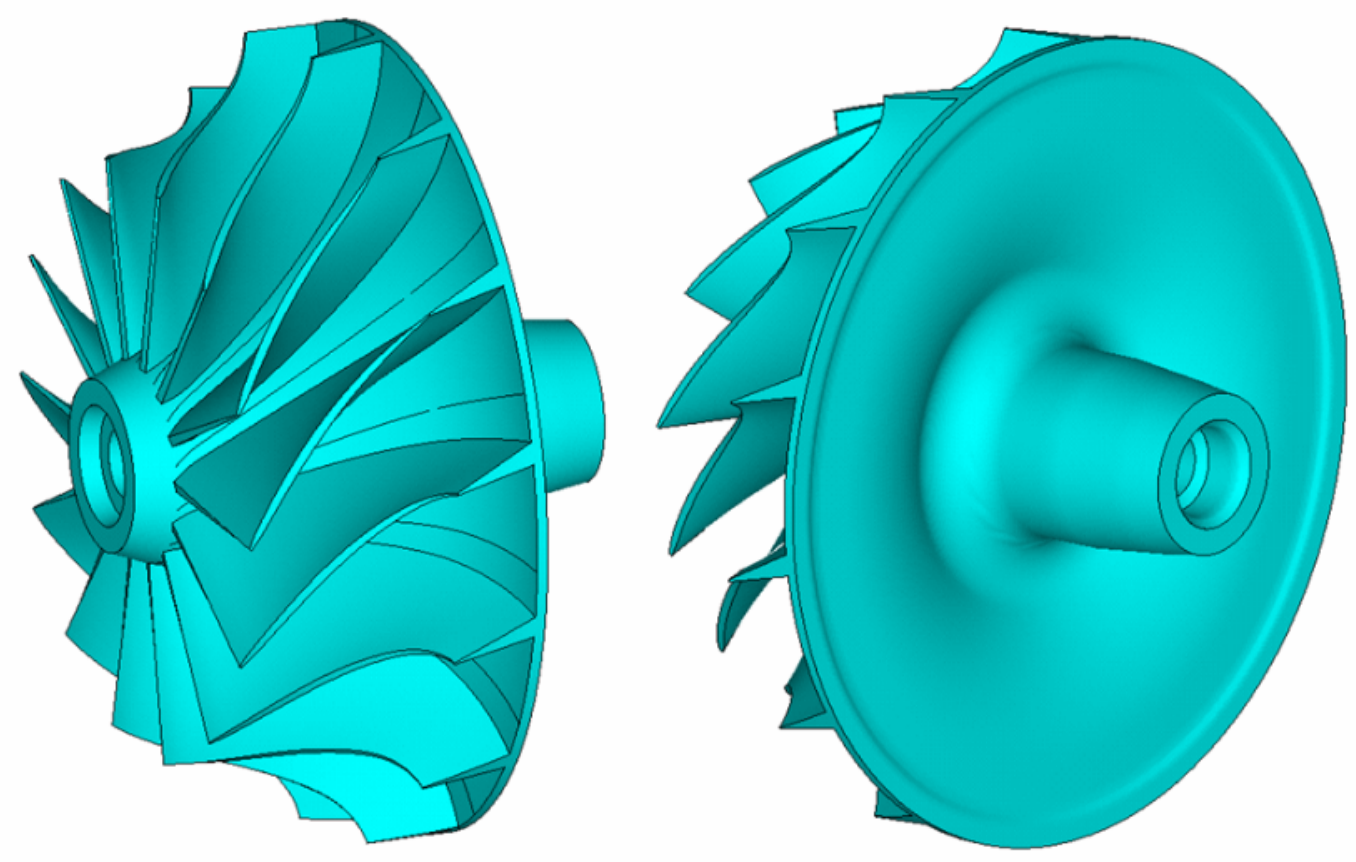

Figure 2: 3D-plots of the single piece impeller in the non-weld-design

\section{Material Selection}

The selection of the materials for the parts of this hot gas-expander is governed by the required mechanical properties defined by the design at the temperature of $500^{\circ} \mathrm{C}$, the gas constituent with traces of halogens and some corrosive halides beside traces of acetic acid.

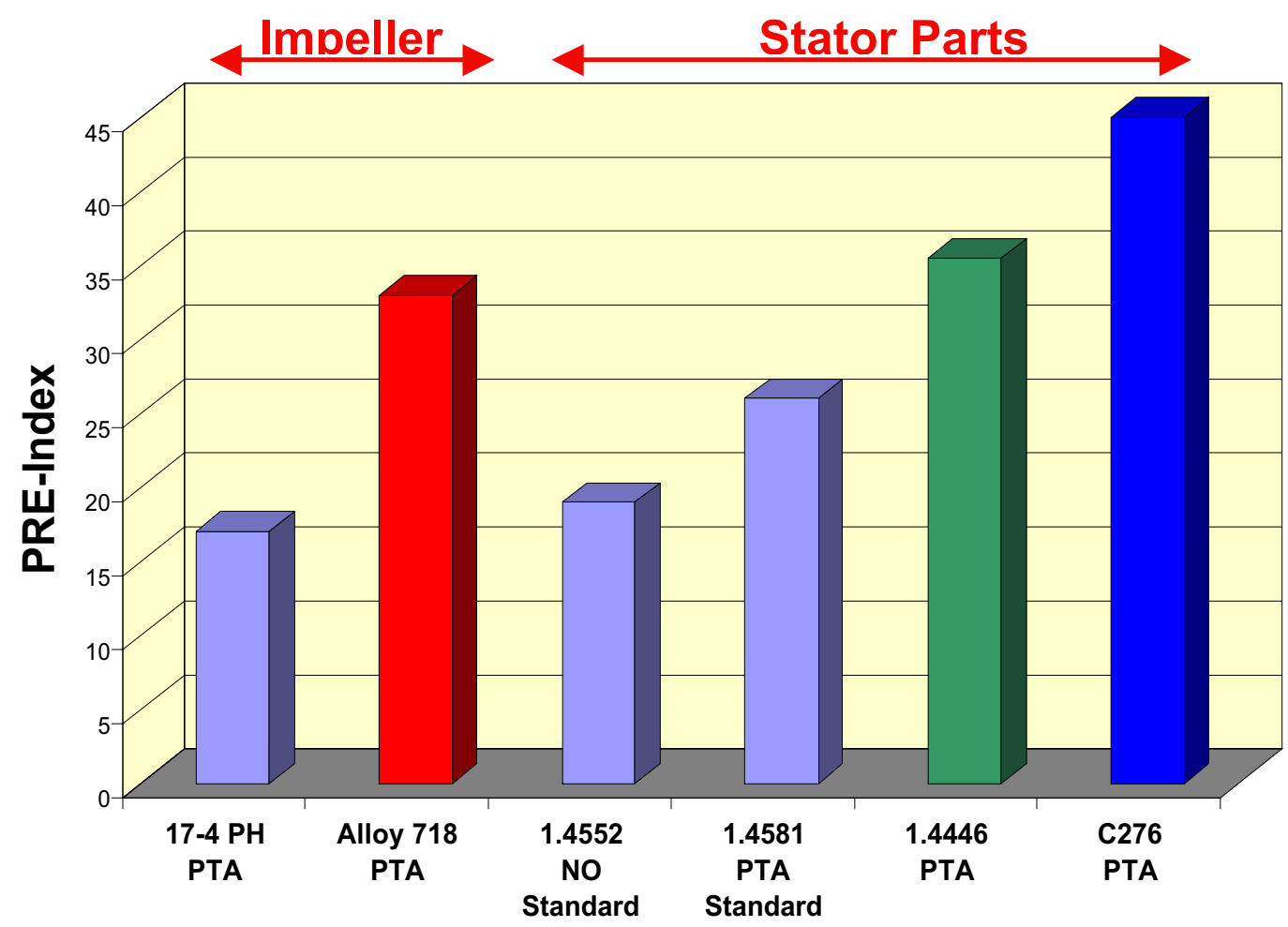

Figure 3: Calculated PRE-Index of some corrosion resistant material. 
The best way to define the corrosion resistance in case of halogen attack is given by the Pitting Resistance Equivalent Index called "PRE" [1].

This Index is shown in Figure 3 as calculated with:

$$
\mathrm{PRE}=\% \mathrm{Cr}+3.3 \mathrm{X} \% \mathrm{Mo}+30 \mathrm{X} \% \mathrm{~N}
$$

(DIN 81249)

for the materials used in the main parts of the expander. Where as austenitic casting (Material Nr.1.4552, 1.4581, 1.4446 according to DIN EN 10027) [2] and Alloy C263 can be used only for low stressed static parts because of low strength, the choice for the impeller was Alloy 718, which has much higher corrosion resistance than a stainless steel 17-4 PH used usually as impeller and the necessary mechanical properties at the high temperature to sustain the substantial stresses at room temperature as well at the service conditions.

\section{Impeller}

The material for the impeller and a number of other parts was chosen to be Alloy 718 because this guarantees best corrosion resistance in conjunction with best mechanical properties at high temperatures.

Alloy 718 is a nickel based super alloy used in a wide range of applications such as high temperature material for aircraft engines parts or high strength material in land based turbines, but also as high corrosion resistance material in the off-shore industry.

The requirement for this very special application was at a temperature of $450^{\circ} \mathrm{C}$ :

- Yield strength of $\mathrm{R}_{\mathrm{P}, 2}=1000 \mathrm{MPa}$ minimum

- Tensile strength of $\mathrm{R}_{\mathrm{M}}=1200 \mathrm{MPa}$ minimum

- Elongation of $\quad \mathrm{A}_{5}=17 \% \quad$ minimum

- Reduction of area $Z=25 \%$ Minimum

The component size of these impeller became a critical issue.

Since the low pressure impeller has a diameter of $1120 \mathrm{~mm}$ and a height of $610 \mathrm{~mm}$, it became the largest forging ever produced in Alloy 718 used by MAN TURBO. Due to the requirement that only a single piece forging of good homogenous quality was to be used, the largest ever produced free-form forging in Alloy 718 resulted as far as known to us. The contour of $\varnothing 1130 / 630$ forging with the rod to be produced in a closed die requires a set of pre-and finishforging tools. Moreover as these expanders are all tailor made, so the repetition of the same size is less probable and the very high forces required of the forging press led to the conclusion to produce these in free-form forging, as the alternatives were prohibitively costly. The heaviest 718 free-form forging made previously, as far as known to us for rotating components was about $4000 \mathrm{kgs}$. The production of the low pressure impeller with a machined diameter of $1120 \mathrm{~mm}$ and height of $610 \mathrm{~mm}$, weighs over $6000 \mathrm{kgs}$ as a pancake in the rough forged machined condition. These impellers were manufactured at SAARSCHMIEDE which is a major supplier of open-die forgings from high alloyed material. For more than 40 years nickel and cobalt based alloys have been manufactured, for aircraft engines, land based turbines, compressors, for application in the off-shore and medical industry as well as for tooling in the drop forging industry. Based on the state of the art facilities like a new 16 t-vacuum-induction-furnace (VIM) 
electroslag remelting (ESR), vacuum arc remelting (VAR) as well as a new 8.500 mt-press SAARSCHMIEDE has made a lot of different products in alloy 718, but these large impeller and the necessary ingots were a big challenge.

\section{Melting}

Alloy 718 is very well known from the aircraft engine parts. But these are made usually from small ingots with a diameter of $500 \mathrm{~mm}$. Alloy 718 is very sensitive to segregations such as freckles, centre segregations or dirty white spots and this tendency increases with larger ingots. The high niobium content of more than $5 \%$ and additional elements like Titanium, Aluminium and Chromium as well as trace elements of Carbon and Nitrogen initiate a lot of phases like carbides, carbonitrides which can result in macro segregations during the solidification in the remelting process.

The melting practise was specified to be VIM-ESR-VAR a triple melting process to minimise all the remelting related defects in the big VAR ingot. After melting an ingot by a vacuum induction process (VIM), a first remelting is done by electroslag remelting process (ESR) followed by the second remelting by vacuum arc remelting process (VAR). The metal was primary melted in a 16 mtonnes vacuum induction furnace (VIM). The chemical composition of the VIM-melt and the check analysis is shown in Figure 4.

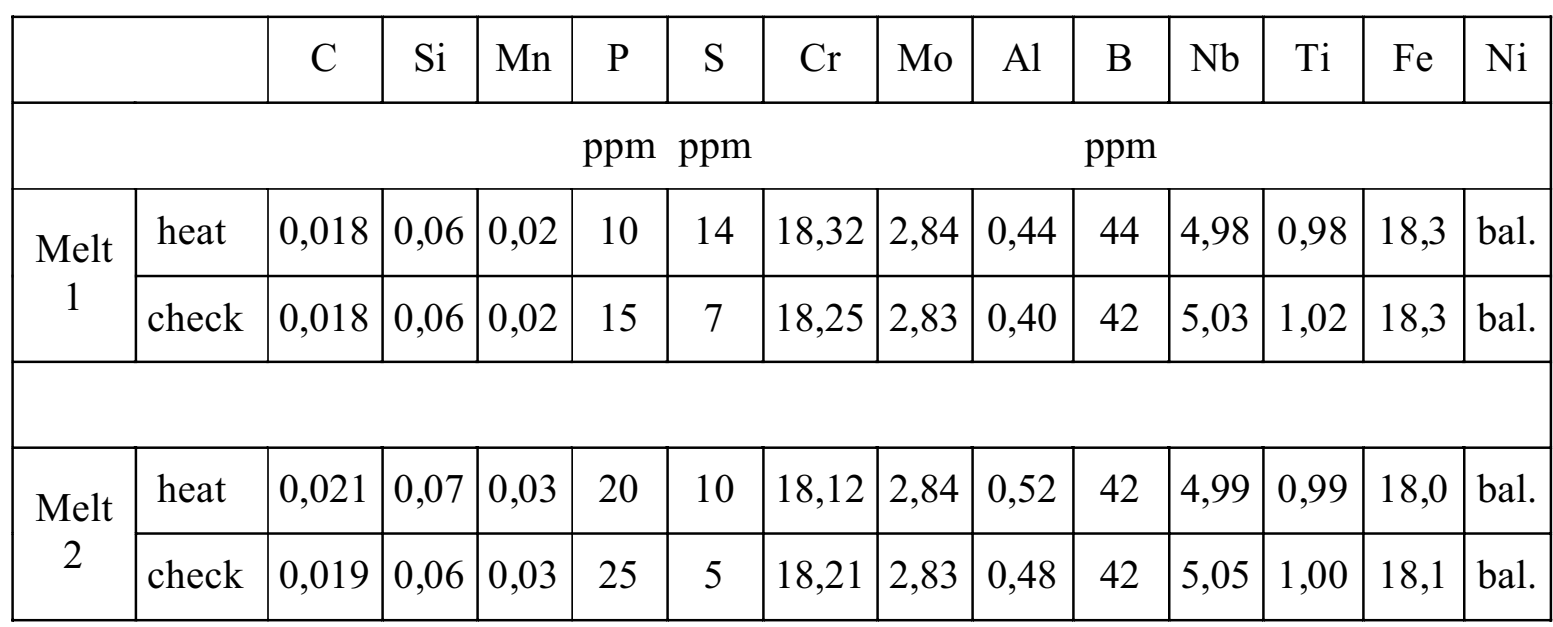

Figure 4: Chemical Analysis of the VIM Ingots in $w t \%$ except otherwise stated

The poured VIM electrodes were electro slag remelted (ESR) to an ingot diameter of $750 \mathrm{~mm}$. The intermediate step of ESR avoids shrinkage cavities and cracks in the ESR-electrodes for the VAR process. This results in a stable VAR process. Further advantage of the intermediate electro slag remelting is an additional removing of oxide and other inclusions. This ESR ingot was forged and cleaned to an electrode suitable for vacuum arc remelting (VAR) in a diameter of $655 \mathrm{~mm}$ crucible. Important factor for avoiding or minimizing the mentioned segregations is to minimize the solidification time in the VAR-process and the optimised variation of the solidification rate. It is well known in the industry that VAR Ingots with acceptable segregation have upper limit in their diameter [3]. Our experience says this limit to be nearly $655 \mathrm{~mm}$. 


\section{Forging}

Prior to the billetizing a homogenisation treatment is necessary for solving laves- phases, a niobium rich phase, which is formed during solidification. These laves phase reduces the ductility of the material significantly. These as cast ingots are homogenized at about $1200^{\circ} \mathrm{C}$ prior to forging. The billetizing was undertaken on an $85 \mathrm{MN}$ - open die press, newly installed at SAARSCHMIEDE in 2002. It was done by multiple upsetting (Figure 5) and drawing operations.
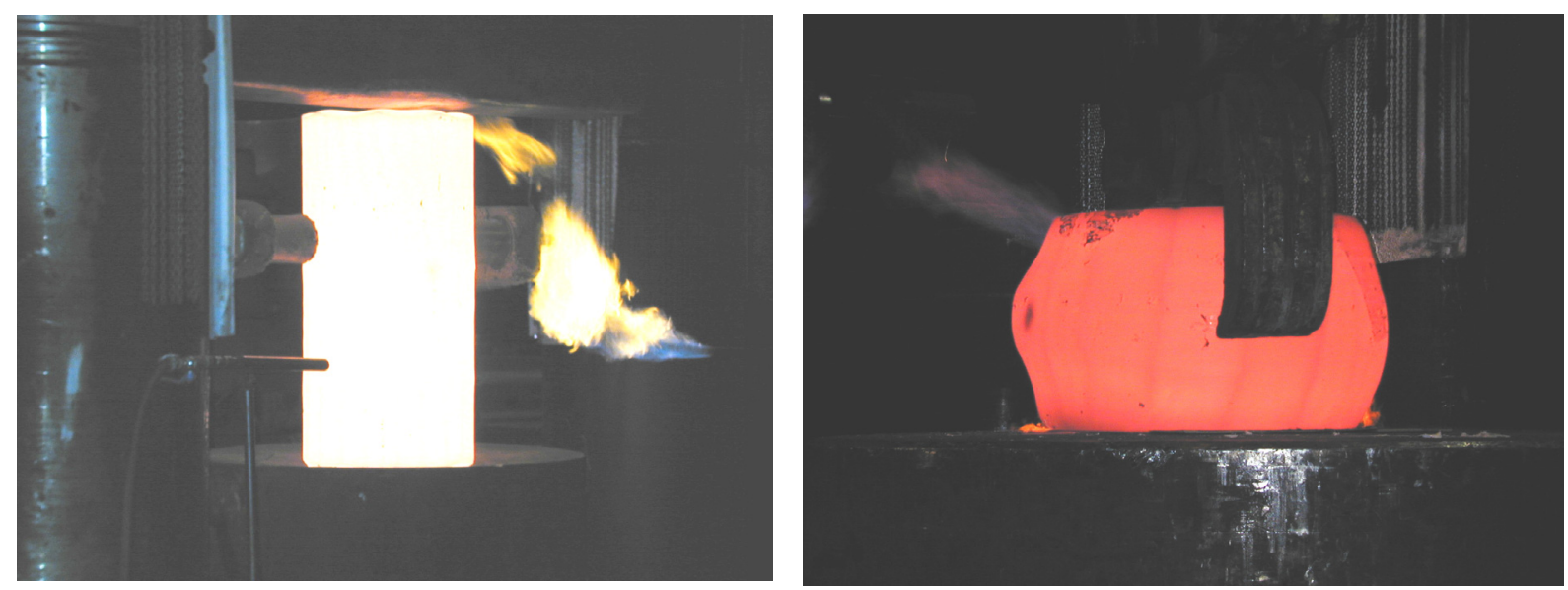

Figure 5: Billetizing and upsetting

The billet diameter was $780 \mathrm{~mm}$. After cutting the top and bottom scrap a forging length of nearly $1.550 \mathrm{~mm}$ was achieved. Prior to final forging the billet was conditioned. The disc forging was performed similar to the process with alloy 706 disc forging [4]. The billet was upset approximately 2:1 in one stroke. This was followed by a series of passes consisting of multiple strokes to step across the face of the disc, which was also rotated between the passes to eliminate structural gradients.

The finished forging dimensions were diameter $1.200 \times 670 \mathrm{~mm}$ which resulted in a forging weight of approximately 6,1 mtonnes. It was difficult to maintain low forging temperatures to achieve a fine grain size in the final product. The high flow stress of alloy 718 at low temperatures challenges the capability of a large force press for an open die forging.

\section{Heat Treatment}

The so forged disc was heat treated, at first the typical solutioning at $960^{\circ} \mathrm{C}$. The two step aging was performed after near finish machining of the impellers. After the solution heat treatment the forged disc was premachined contour for ultrasonic testing. The test rings were taken at outside and inside positions for mechanical and micro structural, then treated in a simulation aged conditions and the testing was done.

The shape of the as forged, as premachined and as machined disc for delivery is shown in Figure 6. 


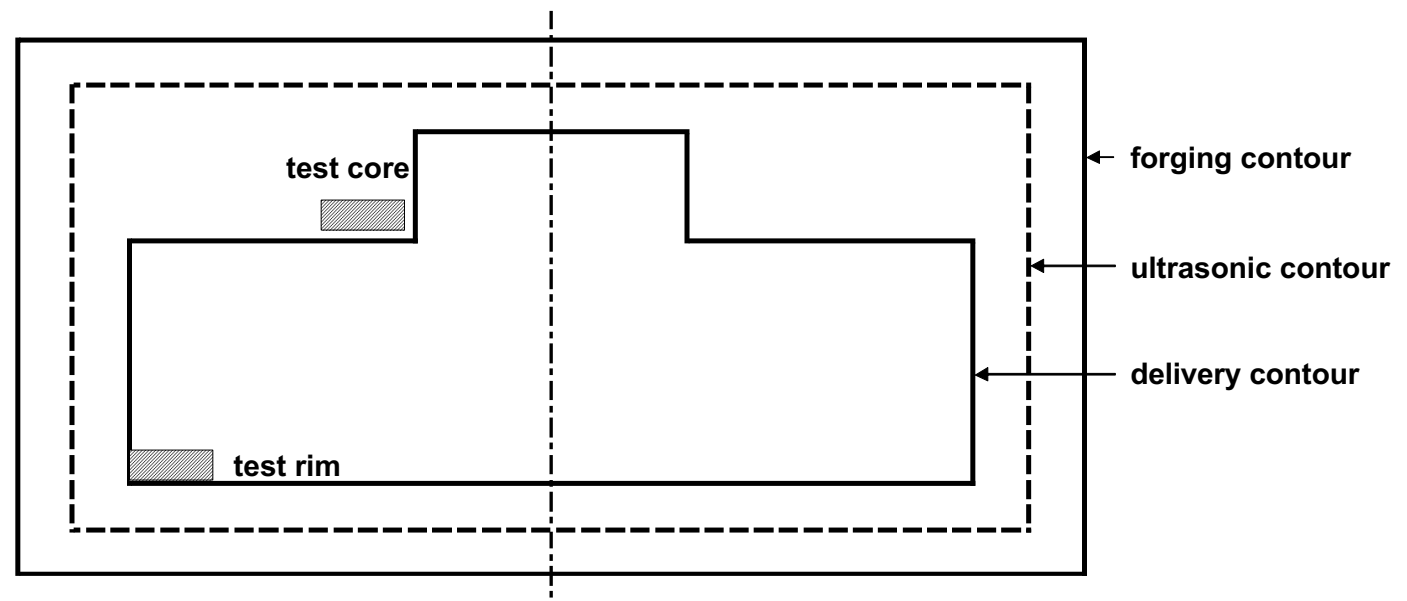

Figure 6: Contours of the forging at different stages and test location

\section{Testing}

\section{Ultrasonic Testing}

The full size forging in the solution treated and premachined condition was inspected by an automated system using a $2 \mathrm{MHz}$ transducer. No reportable indications were found. The minimum detectable defect size (MDDS) was determined to $1.5 \mathrm{~mm}$ for the axial and $1.9 \mathrm{~mm}$ for the radial direction.

\section{Mechanical Properties}

Mechanical properties were determined from the described test rings at room temperature (Figures 7+8) and at $450^{\circ} \mathrm{C}$ (Figures 9+10).

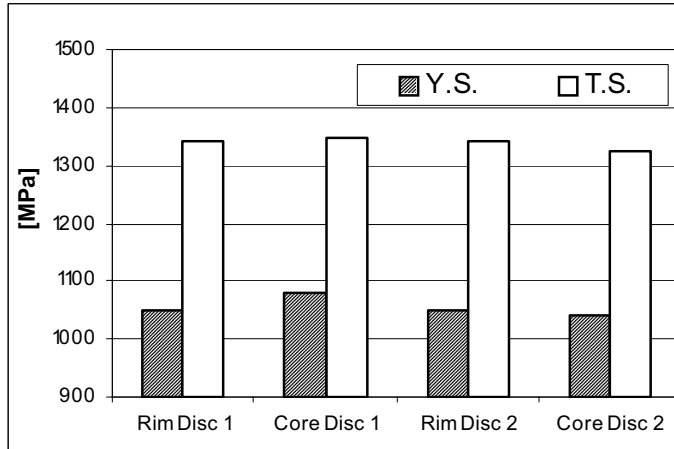

Figure 7: Yield strength and Tensile strength at room temperature

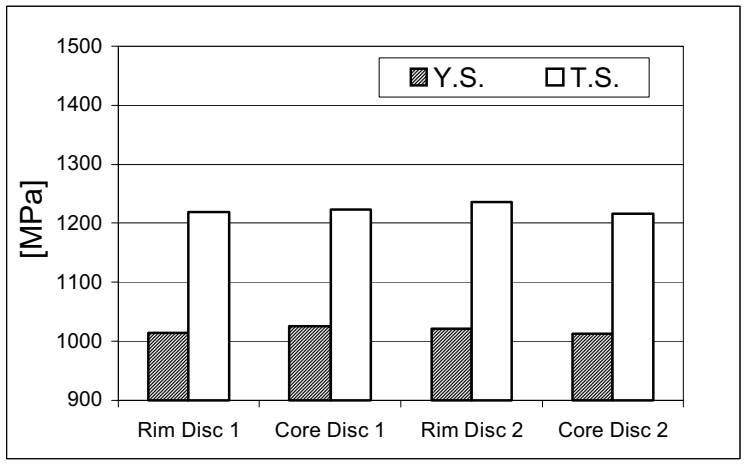

Figure 9: Yield and Tensile strength at $450^{\circ} \mathrm{C}$

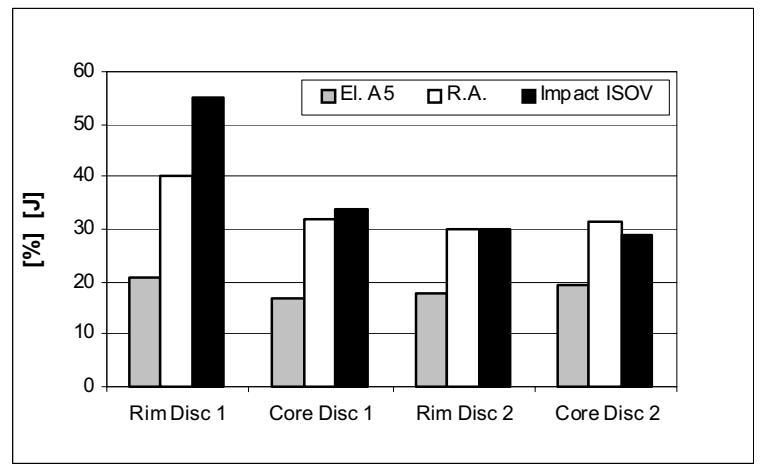

Figure 8: Elongation, R.A. and impact at room temperature

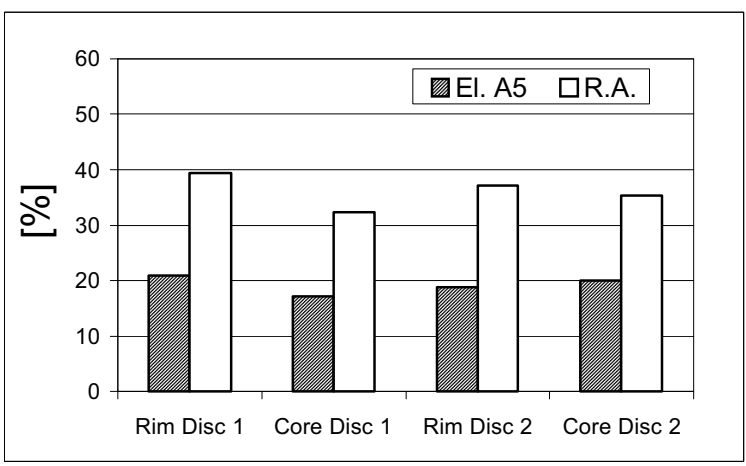

Figure 10: Elongation and R.A. at $450^{\circ} \mathrm{C}$ 


\section{Microstructure}

The grain size was determined according ASTM Standard E112. At both test locations, rim and core, the grain size is $4-5.5$ with occasionally larger grain of 3 as shown in Figure 11.
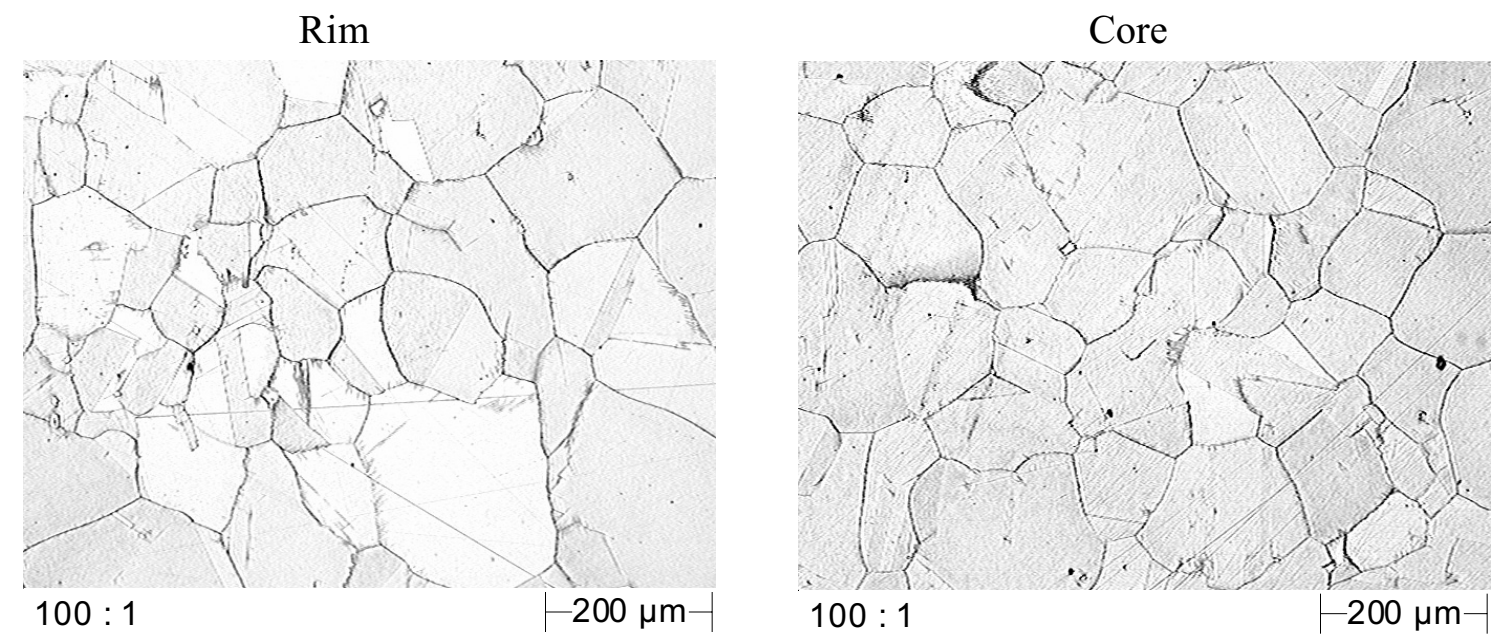

Figure 11: Microstructures at rim and core

\section{Summary}

The production of low pressure impellers open die forged from triple melt 718 ingots with a diameter of $655 \mathrm{~mm}$ and more than $6.000 \mathrm{kgs}$ has been successful. The melting and forging techniques are evaluated in such a manner that the mechanical properties, the microstructure and the soundness of the forgings are within the specified requirements. There is no significant difference in measured properties between rim and core position.

The above results have shown that with proper control of the melting, forging and heat treatment processes it is possible to achieve a uniform grain structure and mechanical properties in large open die alloy 718 forgings.

\section{References:}

[1]: DIN 81249 (1997), Part 1-4 Corrosion of metals in sea water and sea atmosphere, DIN Deutsche Institute für Normung e.V. 10722 Berlin.

[2]: DIN EN 10027 (1992) as in [1].

[3]: Thamboo,S.V., R.C.Schwant, L.Yang, L.A.Jackman, B.J.Bond, R.L.Kennedy : “ Large Diameter 718 Ingots for Land-Based Gas Turbines", Superalloys 718,625,706 and various Derivates, (Edited by E.A. Loria, 2001) p 57-70

[4]: Schoenfeld, K.H., B.Donth, M.G.Cambi, S.V. Thamboo, M.P.Manning: "Manufacturing and Properties of a large Alloy 706 Disc made by the Open Die Forging Process", Superalloys

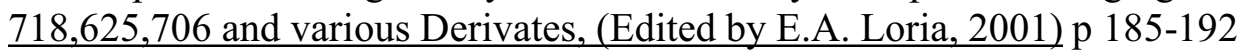

